\title{
Avoiding the classical resolution during the synthesis of MeO-BIPHEP and 3,3'-disubstituted derivatives
}

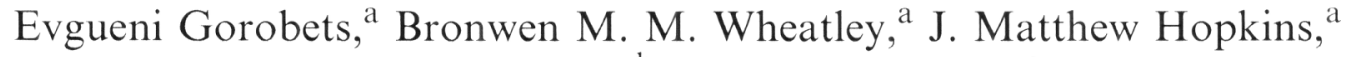 \\ Robert McDonald ${ }^{\mathrm{b}}$ and Brian A. Keay ${ }^{\mathrm{a}, *}$ \\ "Department of Chemistry, University of Calgary, Calgary, AB, Canada T2N $1 N 4$ \\ ${ }^{\mathrm{b}}$ Department of Chemistry, University of Alberta, Edmonton, AB, Canada T6G $2 G 2$ \\ Received 7 March 2005; revised 28 March 2005; accepted 28 March 2005 \\ Available online 12 April 2005
}

\begin{abstract}
The Ullmann coupling of $1(\mathrm{R}=\mathrm{H})$ gives a $2: 1$ mixture of diastereomers $2(\mathrm{R}=\mathrm{H})$ in $81 \%$ yield that are easily separated by silica gel chromatography. This procedure avoids the generally cumbersome and sometimes difficult resolution step with DBTA. Similar Ullmann couplings and separation of the corresponding diastereomers are employed with other derivatives of $1(\mathrm{R}=\mathrm{O} t \mathrm{Bu}$, $i \mathrm{Pr}, \mathrm{Ph}$, and mesityl) ultimately affording a new series of 3,3'-disubsituted-MeO-BIPHEP derivatives. The use of these new derivatives in palladium-catalyzed asymmetric Heck reaction, Pd-catalyzed polyene cyclizations and rhodium-catalyzed hydrogenations is also reported.
\end{abstract}

(c) 2005 Elsevier Ltd. All rights reserved.

We recently reported the synthesis, resolution, and applications of a variety of 3,3'-disubstituted BIPHEP derivatives $\left(3,3^{\prime}\right.$ groups $=$ OMe, OiPr, OPiv, and OTolyl). ${ }^{1}$ In order to compare their efficacy in asymmetric reactions with that of MeO-BIPHEP 11 (Scheme 2), we embarked on preparing $\mathbf{1 1}$ according to the procedure reported by Schmid et al. ${ }^{2,3}$ but quickly found the resolution step with dibenzoyl-L-tartaric acid ((-)DBTA) or di-p-toluoyl-L-tartaric acid ((-)-DTTA) to be cumbersome. Since then, we have experienced similar resolution problems with some of our newer 3,3'-disubstituted MeO-BIPHEP derivatives 3-6 (3,3' groups $=\mathrm{O} t \mathrm{Bu}, i \mathrm{Pr}, \mathrm{Ph},{ }^{4}$ and mesityl) and thus embarked on designing a new synthesis of MeO-BIPHEP 11 that would alleviate the need for a classical resolution step. Herein we report our new synthetic strategy toward the preparation of phosphine oxides 2-6 that involved the attachment of a substrate bound chiral auxiliary to a suitable Ullmann precursor (i.e., 1) (Scheme 1), so that upon affecting an Ullmann coupling diastereomers would be formed that could be easily separated by column chromatography. ${ }^{5}$ In addition, the corresponding phosphines of $\mathbf{3 - 6}$ are used in some asymmetric transformations.

We started by redesigning the synthesis toward $\mathrm{MeO}$ BIPHEP (Scheme 2) to allow for the incorporation of a chiral auxiliary prior to the Ullmann coupling.

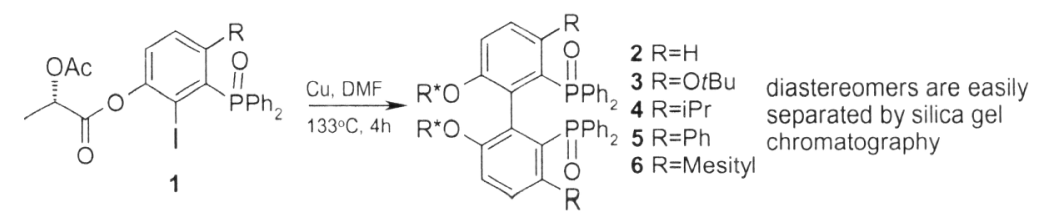

Scheme 1.

Keywords: Ullmann coupling; BIPHEP derivatives.

*Corresponding author. Tel.: +1 403220 5340; fax: +1 403284 1372; e-mail: keay@ucalgary.ca 


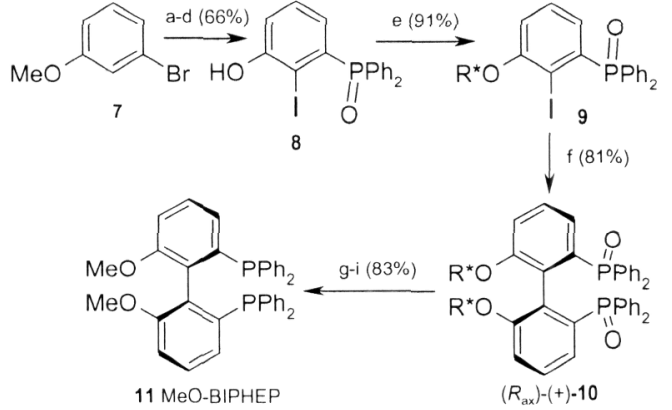

Scheme 2. Reagents and conditions: (a) $n$-BuLi, THF, $-78^{\circ} \mathrm{C}, 1 \mathrm{~h}$, then $\mathrm{Ph}_{2} \mathrm{PCl},-78^{\circ} \mathrm{C}$ to rt, $2 \mathrm{~h}$; (b) $\mathrm{H}_{2} \mathrm{O}_{2}, \mathrm{MeOH}, \mathrm{rt}, 0.5 \mathrm{~h}(93 \%$ two steps); (c) LDA, THF, $-78^{\circ} \mathrm{C}, 1.5 \mathrm{~h}$; then $\mathrm{I}_{2}, \mathrm{THF},-78^{\circ} \mathrm{C}$ to $\mathrm{rt}, 1 \mathrm{~h}$ (76\%); (d) $\mathrm{BBr}_{3}$, DCM, rt, $12 \mathrm{~h}(93 \%)$; (e) (S)-2-acetoxypropanoyl chloride, TEA, DCM, rt, 1 h (91\%); (f) Cu powder, DMF, $150^{\circ} \mathrm{C}, 3 \mathrm{~h}$; separation of diastereomers by silica gel chromatography ( $76 \%$ both diastereomers); (g) $\mathrm{KOH}$, EtOH, rt, $0.5 \mathrm{~h}$; (h) Mel, DCM, $\mathrm{H}_{2} \mathrm{O}$, Adogen, rt, 24 h ( $94 \%$ two steps); (i) $\mathrm{Cl}_{3} \mathrm{SiH}, n-\mathrm{Bu}_{3} \mathrm{~N}$, xylene, $145^{\circ} \mathrm{C}$, 24 h $\left(89^{\prime \prime} \%\right)$.

Halogen-metal exchange of bromide 7 with $n$-BuLi followed by the addition of $\mathrm{ClPPh}_{2}{ }^{6}$ and $\mathrm{H}_{2} \mathrm{O}_{2}{ }^{7}$ gave a phosphine oxide that when treated with LDA at $-78{ }^{\circ} \mathrm{C}$ in THF followed by iodine gave 8 after removal of the methyl group with $\mathrm{BBr}_{3}$. Reaction of $\mathbf{8}$ with $(S)-2-$ acetoxypropanoyl chloride ${ }^{8}$ gave $\mathbf{9}$, which was subjected to an Ullmann coupling ${ }^{9}$ to give a $33 \%$ de in favor of diastereomer $\left(R_{\mathrm{ax}}\right)-(+)-\mathbf{1 0}$. The diastereomers were easily separated by silica gel chromatography, with the diastereomer with the $S_{\mathrm{ax}}$ configuration always having the larger $R_{\mathrm{f}}$. Removal of the chiral auxiliary $(\mathrm{KOH}$, EtOH), methylation (MeI, Adogen), and trichlorosilane reduction ${ }^{10}$ of the phosphine oxides provided MeO-BIPHEP 11. Although the sequence is two steps longer than the original, a resolution step was not necessary and the diastereomers from the Ullmann coupling were easily separated.

The diastereomeric Ullmann coupling strategy was applied to the synthesis of ligands $\mathbf{2 3}, \mathbf{2 9}$, and $\mathbf{3 4}$. Compound (+)-23 was prepared in twelve steps from hydroquinone 12 as outlined in Scheme 3. The Ullmann coupling of 20 provided a $24 \%$ de in favor of $\left(R_{\mathrm{ax}}\right)-(+)$ 21. The diastereomers of $\mathbf{2 1}$ were separated and the $R_{\mathrm{ax}}-$ isomer carried on to compound $\left(R_{\mathrm{ax}}\right)-(+)-23 .{ }^{11} \mathrm{Com}-$ pound $(+)$-29 was prepared in 15 steps from $\mathbf{2 4}$ (Scheme 4). Ullmann coupling of 27 again gave a $3: 2$ mixture of $\left(R_{\mathrm{ax}}\right)$-28 and $\left(S_{\mathrm{ax}}\right)$-28 that were easily separated by column chromatography. Finally, Ullmann coupling of 32 gave a 1:1.3 mixture of diastereomers 33 (Scheme 5) that was eventually converted into compound $\left(R_{\mathrm{ax}}\right)-\mathbf{3 4}$ in 12 steps from 2-bromo-4-methoxyaniline $(\mathbf{3 0}) \cdot{ }^{12}$ The same sequence outlined in Scheme 5 was used to prepare the 3,3'-dimesitylene compound 35. Removal of the chiral auxiliary from (+)-35 and methylation gave (-)-36. Reduction of $(-)-\mathbf{3 6}$ with $\mathrm{Cl}_{3} \mathrm{SiH}$ resulted in the reduction of only one of the two phosphine oxides in $25 \%$ yield $(75 \%$ unreacted (-)-36). Changing the reaction conditions never afforded the desired bis-phosphine. Interestingly, treatment of (-)-36 with alane unexpectedly gave compound 37 .

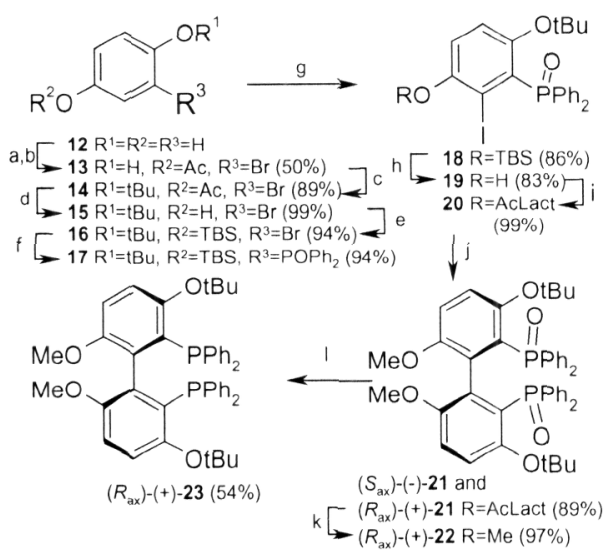

Scheme 3. Reagents and conditions: (a) $\mathrm{Ac}_{2} \mathrm{O}, \mathrm{AcOH}, \mathrm{rt}, 1 \mathrm{~h}$; (b) $\mathrm{Br}_{2}$, $\mathrm{CHCl}_{3}, 0^{\circ} \mathrm{C}, 1 \mathrm{~h}$; (c) 2-methyl-propene, DCM, TfOH, $-78^{\circ} \mathrm{C}, 4 \mathrm{~h}$; (d) $\mathrm{KOH}$, EtOH, rt, $15 \mathrm{~min}$; (e) TBSCl, imid, DMC, rt, $1 \mathrm{~h}$; (f) $n$-BuLi, THF, $-78{ }^{\circ} \mathrm{C}, 1 \mathrm{~h}$; then $\mathrm{Ph}_{2} \mathrm{PCl}, 2 \mathrm{~h}$; then $\mathrm{H}_{2} \mathrm{O}_{2}, \mathrm{MeOH}, 0{ }^{\circ} \mathrm{C}, 20 \mathrm{~min}$; (g) LDA, THF, $-78{ }^{\circ} \mathrm{C}, 1.5 \mathrm{~h}$; then $\mathrm{I}_{2},-78{ }^{\circ} \mathrm{C}$ to $\mathrm{rt}, 1.5 \mathrm{~h}$; (h) TBAF, THF, rt, 15 min; (i) (R)-2-acetoxypropanoyl chloride, DCM, TEA, DMAP, $0{ }^{\circ} \mathrm{C}, 30 \mathrm{~min}$; (j) $\mathrm{Cu}, \mathrm{DMF}, 150^{\circ} \mathrm{C}, 6 \mathrm{~h}$; separation of diastereomers by silica gel chromatography $(89 \%$ for both diastereomers); (k) KOH, EtOH, rt, 30 min; then MeI, DCM, Adogen, rt, 12 h; (l) $\mathrm{HSiCl}_{3}$, xylene, $105^{\circ} \mathrm{C}, 24 \mathrm{~h}$.

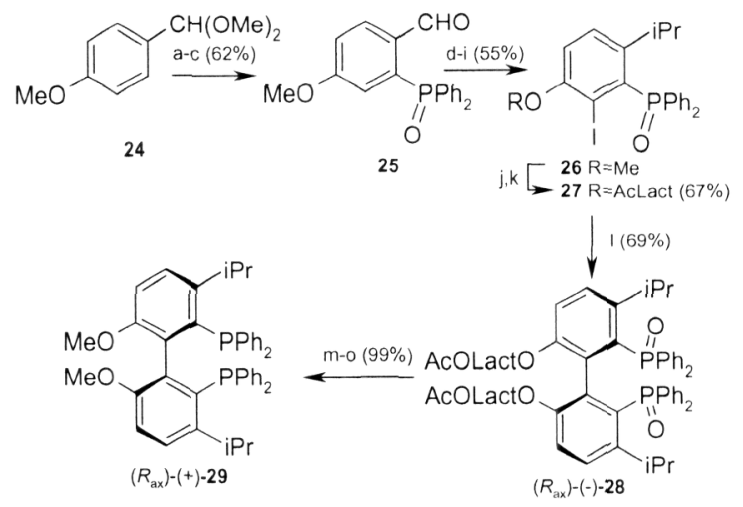

Scheme 4. Reagents and conditions; (a) $t-\mathrm{BuLi}_{2} \mathrm{Et}_{2} \mathrm{O},-25^{\circ} \mathrm{C}, 3 \mathrm{~h}$, then $\mathrm{Ph}_{2} \mathrm{PCl},-78{ }^{\circ} \mathrm{C}$ to rt, $12 \mathrm{~h}$; (b) $\mathrm{H}_{2} \mathrm{O}_{2}, \mathrm{MeOH}, \mathrm{rt}, 1 \mathrm{~h}(68 \%$ two steps); (c) $p \mathrm{TsOH}$, acetone, $\mathrm{rt}, 1.5 \mathrm{~h}(91 \%)$; (d) $\mathrm{MeMgBr}, \mathrm{THF}, 5{ }^{\circ} \mathrm{C}$, $\mathrm{l}$ h; (e) $\mathrm{MnO}_{2}$, acetone, $\mathrm{rt}, 36 \mathrm{~h}$; (f) $\mathrm{MeMgBr}$, THF, rt, $1 \mathrm{~h}$; (g) $\mathrm{Ac}_{2} \mathrm{O}$, $120^{\circ} \mathrm{C}, 24 \mathrm{~h}$; (h) $\mathrm{H}_{2}, \mathrm{Pt}_{2} \mathrm{O}, 1 \mathrm{~atm}, \mathrm{rt}, 6 \mathrm{~h}$; (i) LDA, THF, $-78^{\circ} \mathrm{C}, 1.5 \mathrm{~h}$; then $\mathrm{I}_{2}$, THF, $-78^{\circ} \mathrm{C}$ to rt, $2 \mathrm{~h}\left(55^{\circ} \%\right.$ six steps); (j) $\mathrm{BBr}_{3}, \mathrm{DCM}, \mathrm{rt}, 20 \mathrm{~h}$ $(93 \%)$; (k) (S)-2-acetoxypropanoyl chloride, TEA, DCM, rt, I h $(67 \%$ two steps); (1) $\mathrm{Cu}$ powder, DMF, $133^{\circ} \mathrm{C}, 4 \mathrm{~h}$; separation of diastereomers by silica gel chromatography $(69 \%$ both diastereomers); (m) $\mathrm{KOH}$, EtOH, rt, 1 h; (n) MeI, DCM, $\mathrm{H}_{2} \mathrm{O}$, Adogen, rt, 48 h; (o) $\mathrm{Cl}_{3} \mathrm{SiH}, n$ - $\mathrm{Bu}_{3} \mathrm{~N}$, xylene, $135^{\circ} \mathrm{C}, 48 \mathrm{~h}(99 \%$ three steps $)$.

With (+)-(R)-23, $(+)-(R)-29$, and $(-)-(R)-34$ in hand, we compared the efficacy of these ligands in the asymmetric Heck arylation of 2,3-dihydrofuran and compared the results to those obtained with (+)-MeO-BIPHEP $(\mathbf{1 1}$, Table 1). (+)-MeO-BIPHEP 11 provided 65\% conversion to products and gave $92 \%$ ee of $\mathbf{4 0 , 6 3 \%}$ ee of $\mathbf{4 2}$ along with a small amount of the conjugated product 41 (Table 1, entry 1). The ratio of $\mathbf{4 0 : 4 1 : 4 2}$ was 83:7:10. The best result was with the $3,3^{\prime}-\mathrm{di}-\mathrm{O} t \mathrm{Bu}$ 


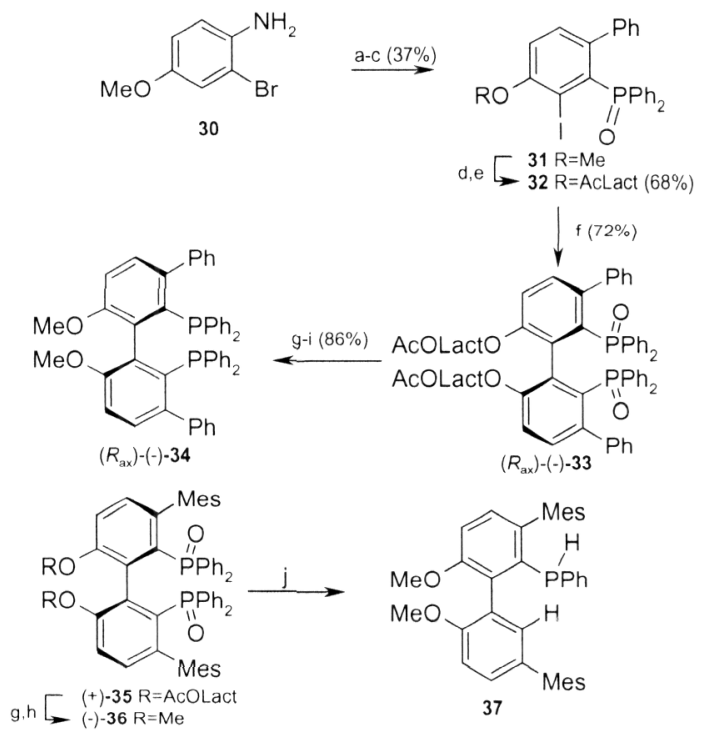

Scheme 5. Reagents and conditions: (a) $n-\mathrm{C}_{5} \mathrm{H}_{11} \mathrm{ONO}$, benzene (or mesitylene), reflux, $1.5 \mathrm{~h}(52 \%)$; (b) $n$-BuLi, THF, $-78^{\circ} \mathrm{C}, 3 \mathrm{~h}$, then $\mathrm{Ph}_{2} \mathrm{PCl},-78^{\circ} \mathrm{C}$ to rt, $12 \mathrm{~h}$; then $\mathrm{H}_{2} \mathrm{O}_{2}, \mathrm{MeOH}, \mathrm{rt}, 1 \mathrm{~h}(91 \%)$; (c) LDA, THF, $-78^{\circ} \mathrm{C}, 1.5 \mathrm{~h}$; then $\mathrm{I}_{2}, \mathrm{THF},-78^{\circ} \mathrm{C}$ to rt, $2 \mathrm{~h}(78 \%)$; (d) $\mathrm{BBr}_{3}$, DCM, rt, $20 \mathrm{~h} \mathrm{(93 \% );} \mathrm{(e)} \mathrm{(S)-2-acetoxypropanoyl} \mathrm{chloride,} \mathrm{TEA,}$ DCM, rt, $1 \mathrm{~h}(72 \%)$; (f) Cu powder, DMF, $145^{\circ} \mathrm{C}, 4 \mathrm{~h}$; separation of diastereomers by silica gel chromatography ( $72 \%$ both diastereomers); (g) $\mathrm{KOH}, \mathrm{EtOH}, \mathrm{rt}, 1 \mathrm{~h}$; (h) MeI, DCM, $\mathrm{H}_{2} \mathrm{O}$, Adogen, rt, 48 h; (i) $\mathrm{Cl}_{3} \mathrm{SiH}, n$-Bu ${ }_{3} \mathrm{~N}$, xylene, $135^{\circ} \mathrm{C}, 48 \mathrm{~h}\left(93^{\circ} \%\right.$ three steps $) ;(j)$ alane, THF, reflux, 3 h $(78 \%)$.

Table 1. Asymmetric Heck results with ligands 11, 23, 29, and 34

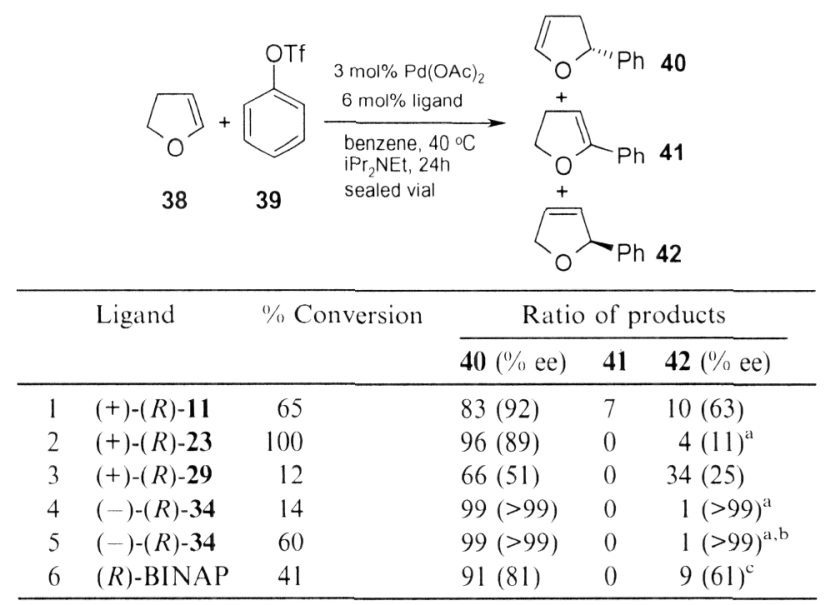

${ }^{a}$ The major enantiomer of $\mathbf{4 2}$ had the $R$-configuration.

${ }^{\mathrm{b}} 10 \mathrm{~mol} \% \mathrm{Pd}(\mathrm{OAc})_{2}, 20 \mathrm{~mol} \%(-)-(R)-34$.

"Results reported by Hayashi and co-workers. ${ }^{13}$

bisphosphine 23 (entry 2). The conversion to products was $100 \%$ with $\mathbf{4 0}$ formed in $96 \%$ yield with $89 \%$ ee. Ligand $\mathbf{2 3}$ well outperformed $(+)-(R)$-BINAP in \% conversion, ratio of $\mathbf{4 0 : 4 2}$ and in \% ee of $\mathbf{4 0} .{ }^{13}$ Both the $3,3^{\prime}$-di$i \operatorname{Pr}$ derivative 29 (entry 29) and 3,3'-di-Ph derivative $\mathbf{3 4}$ (entry 4) gave poor conversions at $3 \mathrm{~mol} \% \mathrm{Pd}$ loading $\left(12 \%\right.$ and $14 \%$, respectively) $;^{14}$ however, when the $\mathrm{Pd}$ loading was increased to $10 \mathrm{~mol} \%$ with ligand $\mathbf{3 4}$, the conversion increased to $60 \%$ in a $24 \mathrm{~h}$ period. It is noteworthy that $\mathbf{3 4}$ gave $\mathbf{4 0}$ not only with a $99 \%$ ee but also with an excellent 40:42 ratio of 99:1 (entries 4 and 5). This is the highest $\%$ ee and product ratio observed to date in our laboratory using a variety of chiral catalysts. ${ }^{1.15}$ Work is continuing to improve the $\%$ conversion with $(-)-(R)-34$.

Ligands $(+)-(R)-\mathbf{2 3},(+)-(R)-\mathbf{2 9}$, and $(-)-(R)-\mathbf{3 4}$ were then used in the palladium catalyzed polyene cyclization $(\mathbf{4 3} \rightarrow \mathbf{4 4})$ and compared to the results obtained with $(+)-(R)-\mathrm{MeO}-\mathrm{BIPHEP}(\mathbf{1 1}$, Table 2$) .(+)-(R)-\mathrm{MeO}-\mathrm{BIP}-$ HEP $(\mathbf{1 1})$ afforded $(R)-\mathbf{4 4}$ in $72 \%$ ee $(53 \%$ yield). The use of the 3,3'-di-O- $t$ Bu ligand $(+)-(R)-23$ gave a comparable yield and slightly lower \% ee than with $\mathbf{1 1}$; however, the absolute stereochemistry of the major enantiomer was opposite of that obtained with $(+)-(R)-11$. This result is in line with the results obtained with other 3,3'-diOR BIPHEP derivatives reported previously. '

3,3'-Di-Ph-BIPHEP derivative (-)-( $R$ )-34 gave a low $53 \%$ yield and disappointing $24 \%$ ee. In this case, the major enantiomer had the $R$-configuration, which was in line with that obtained using $(+)-(R)-11$. Finally, $(+)-(R)-29$ gave $(R)-44$ in excellent yield $(83 \%)$ and with an $80 \%$ ee. This is the highest \% ee we have observed in this reaction to date. ${ }^{1,16}$

Ligands $(+)-(R)-\mathbf{2 3},(+)-(R)-\mathbf{2 9}$, and $(-)-(R)-\mathbf{3 4}$ were then used in catalytic hydrogenations of acid $\mathbf{4 5}$ $(\mathrm{R}=\mathrm{H})$ and ester $\mathbf{4 5}(\mathrm{R}=\mathrm{Me})$ and compared to results obtained with MeO-BIPHEP 11 (Table 3). ${ }^{17}$ While (+)$(R)$-MeO-BIPHEP 11 performed poorly in the hydrogenation of $\mathbf{4 5}$ (entry 1) an improvement was observed with ligand $(+)-(R)-29$. A lower \% ee upon using $(+)$ $(R)-29$ with acid $45(\mathrm{R}=\mathrm{H})$ was surprising given the excellent results with other ligands; repeating the reaction did not change the $\%$ ee. The best results were seen with ligands $(+)-(R)-\mathbf{2 3}$ and $(-)-(R)-\mathbf{3 4}$ with the latter giving the best results on hydrogenation with both the acid and ester of $\mathbf{4 5}$.

Table 2. Asymmetric Pd-catalyzed polyene cyclization results with ligands 11, 23, 29, and 34

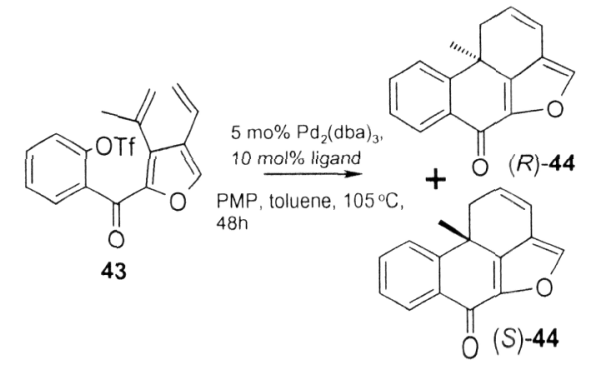

\begin{tabular}{cccccc}
\hline & Catalyst & $\%$ Yield & \multicolumn{2}{c}{$\begin{array}{c}\text { Ratio of } \\
\text { enantiomers }\end{array}$} & \\
\cline { 3 - 5 } & & & $(R)-\mathbf{4 4}$ & $(S)-\mathbf{4 4}$ & \\
\hline 1 & $(+)-(R)-\mathbf{1 1}$ & 53 & $\mathbf{8 6}$ & 14 & 72 \\
2 & $(+)-(R)-\mathbf{2 3}$ & 56 & 19 & $\mathbf{8 1}$ & 62 \\
3 & $(+)-(R)-\mathbf{2 9}$ & 83 & $\mathbf{9 0}$ & 10 & 80 \\
4 & $(-)-(R)-\mathbf{3 4}$ & 53 & $\mathbf{6 2}$ & 38 & 24 \\
\hline
\end{tabular}


Table 3. Asymmetric hydrogenation results with ligands 11, 23, 29 , and 34

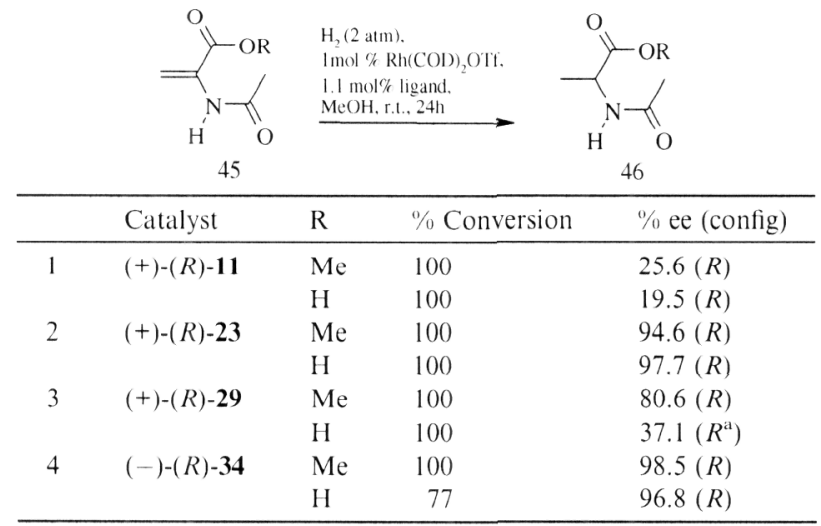

"Reaction attempted twice.

We have shown that a diastereoselective Ullmann coupling using a (+)-2-acetoxypropanoyl group as the chiral auxiliary provides biaryl systems that are easily separated by silica gel chromatography, thereby avoiding the generally cumbersome and sometimes difficult resolution step with (L)-DBTA. Interestingly, ligands (+)$(R)-\mathbf{2 3},(+)-(R)-\mathbf{2 9}$, and $(-)-(R)-\mathbf{3 4}$ each gave the best $\%$ ee's in the Hayashi Heck reaction, palladium-catalyzed polyene cyclization and catalytic hydrogenation of $\mathbf{4 5}$, respectively, indicating that one specific 3,3-disubstituted BIPHEP ligand is not ideal for all asymmetric transformations. Work is continuing to shorten the synthetic routes to 3,3'-disubsituted BIPHEP derivatives and applying these ligands in other asymmetric reactions.

\section{Acknowledgements}

We thank Merck Frosst (Pointe Claire, PQ), NSERC CRD program, and the University of Calgary for financial support. In addition NSERC and the Alberta Ingenuity Fund are thanked for postgraduate scholarships (for B.M.M.W. and J.M.H.).

\section{Supplementary data}

Experimental procedures for the diastereoselective Ullmann coupling of $\mathbf{9}, \mathbf{2 0}, \mathbf{2 7}$, and $\mathbf{3 2}$ are provided. The $\mathrm{X}$-ray crystal structure of $\mathbf{3 7}$ is also provided. Supplementary data associated with this article can be found, in the online version, at doi:10.1016/j.tetlet.2005.03.183.

\section{References and notes}

1. Gorobets, E.; Sun, G.-R.; Wheatley, B. M. M.; Parvez, M.; Keay, B. A. Tetrahedron Lett. 2004, 45, 3597-3601.

2. (a) Schmid, R.; Cereghetti, M.; Heiser, B.; Schonholzer, P.; Hansen, H.-J. Helv. Chim. Acta 1988, 71, 897; (b) Schmid, R.; Foricher, J.; Cereghetti, M.; Schönholzer, P. Helv. Chim. Acta 1991, 74, 370-389.

3. Another reason for preparing $\mathbf{1 1}$ is its high cost from Aldrich Chemical Co. $2005-06$ price $=\$ 0.86 / \mathrm{mg}(\$ C d n)$.

4. (a) The synthesis of 3,3'-diphenyl MeO-BIPHEP was recently reported by Zhang and co-workers and involved a resolution step with (L)-DTTA: Wu, S.; He, Minsheng; Zhang, X. Tetrahedron: Asymmetry 2004, 15, 2177-2180; (b) Tang, W.; Chi, Y.; Zhang, X. Org. Lett. 2002, 4, 1695; (c) Tang, W.; Zhang, X. Chem. Rev. 2003, 103, 3029-3069.

5. We were not concerned about achieving high diastereoselectivity in the Ullmann coupling as both enantiomers of the various BIPHEP derivatives were required for application purposes.

6. Hall, T. J.; Hargis, J. H. J. Org. Chem. 1986, 51, 41854189

7. Hamashima, Y.; Kanai, M.; Shibasaki, M. Tetrahedron Lett. 2001, 42, 691-694.

8. (S)-2-Acetoxypropanoyl chloride is available from Aldrich.

9. Hassan, J.; Sévignon, M.; Gozzi, C.; Schulz, E.; Lemaire, M. Chem. Rev. 2002, 102, 1359-1469.

10. Takaya, H.; Mashima, K.; Yagi, M.; Kumobayashi, H.; Taketomi, T.; Akutagawa, S.; Noyori, R. J. Org. Chem. 1986, 51, 629-635.

11. The lower yield of $54 \%$ was due to loss of some of the $t$ butyl group in the presence of $\mathrm{Cl}_{3} \mathrm{SiH}$ at $105^{\circ} \mathrm{C}$.

12. Ishibashi, H.; Kobayashi, T.; Machida, N.; Tamura, O. Tetrahedron 2000, 56, 1469-1473.

13. (a) Ozawa, F.; Kubo, A.; Matsumoto, Y.; Hayashi, T. Organometallics 1993, 12, 4188; (b) Ozawa, F.; Kubo, A.; Hayashi, T. J. Am. Chem. Soc. 1991, 113, 1417.

14. Stirring the reaction longer did not increase the $\%$ conversion. We are continuing to investigate why the reaction appears to stall with ligands 29 and 34.

15. Andersen, N. G. Ph.D. Dissertation, University of Calgary, 2000.

16. (a) Lau, S. Y. W.; Keay, B. A. Synlett 1999, 605-607; (b) Lau, S. Y. W.; Andersen, N. G.; Keay, B. A. Org. Lett. 2001, 3, 181-184; (c) Che, D.; Andersen, N. G.; Lau, S. Y. W.; Parvez, M.; Keay, B. A. Tetrahedron: Asymmetry 2000, 11, 1919-1925; (d) Andersen, N. G.; McDonald, R.; Keay, B. A. Tetrahedron: Asymmetry 2001, 12, 263-269; (e) Maddaford, S. P.; Andersen, N. G.; Cristofoli, W. A.; Keay, B. A. J. Am. Chem. Soc. 1996, 118, 10766-10773; (f) Keay, B. A.; Maddaford, S. P.; Cristofoli, W. A. Andersen, N. G.; Passafaro, M. S.; Wilson, N. S.; Nieman, J. A. Can. J. Chem. 1997, 75, 1163-1171.

17. Li, W.; Zhang, Z.; Xiao, D.; Zhang, X. J. Org. Chem. 2000, 65, 3489-3496. 